
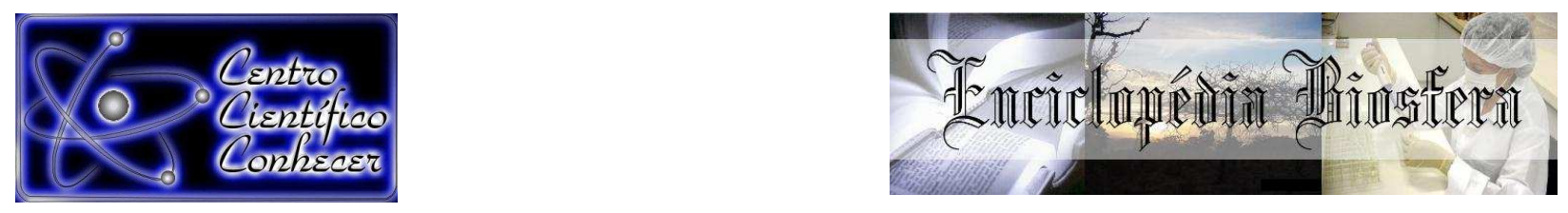

\title{
DIAGNÓSTICO AMBIENTAL DA ÁREA DE PRESERVAÇÃO PERMANENTE NO ALTO CURSO DO CÓRREGO DOIS IRMÃOS EM GURUPI-TO
}

\footnotetext{
Virgílio Lourenço Silva Neto ${ }^{1}$, Diógenis Fontenele Ferreira Junior ${ }^{2}$, Patrícia Aparecida de Souza ${ }^{3}$, Marcelo Ribeiro Viola ${ }^{4}$

1 Mestrando do Programa de Pós-graduação em Ciências Florestais e Ambientais da Universidade Federal do Tocantins - UFT, Professor do Instituto Federal do Tocantins-IFTO, Campus Dianópolis, email: virgilio.neto@ifto.edu.br, Dianópolis (TO) - Brasil

2 Mestrando do Programa de Pós-graduação em Ciências Florestais e Ambientais da Universidade Federal do Tocantins - UFT

3 Professora Doutora do Curso do Programa de Pós-Graduação em Ciências Florestais e Ambientais

4 Professor Adjunto do Departamento de Engenharia da Universidade Federal de Lavras, Departamento de Engenharia do Solo

Recebido em: 08/04/2016 - Aprovado em: 30/05/2016 - Publicado em: 20/06/2016 DOI: 10.18677/Enciclopedia_Biosfera_2016_042
}

\begin{abstract}
RESUMO
A Área de Preservação Permanente do Córrego Dois Irmãos, situada na cidade de Gurupi-TO, importante na proteção de um valioso recurso hídrico, sofre com a destruição da mata ciliar, erosão e uso inadequado do solo. Considerando as implicações legais e ambientais, o objetivo deste estudo diagnosticar e analisar os impactos decorrentes da ocupação urbana irregular na APP do córrego dois irmãos no município. Foram realizadas visitas técnicas, elaboração de um check-list com os principais problemas identificados, levantamento de imagens de satélites (CNES/Astrium Digital Globe). As imagens foram georreferenciadas e processadas no software ArcGis 9.3, que permitiu a delimitação da área de estudo e análise do avanço da degradação. Dentre os principais impactos observados, encontra-se a destruição da vegetação ciliar, que somado a outros impactos são responsáveis pela degradação de 50,6\% da APP no alto curo do córrego, causando a perturbação do ecossistema.
\end{abstract}

PALAVRAS-CHAVE: degradação, mata ciliar, mananciais, recuperação

\section{ENVIRONMENTAL DIAGNOSIS OF PERMANENT PRESERVATION AREA IN HIGH COURSE OF STREAM DOIS IRMÃOS}

\begin{abstract}
The Permanent Preservation Area Stream Two Brothers, located in the city of Gurupi-TO, important in protecting valuable water resources, suffers with the destruction of riparian vegetation, erosion and inappropriate use of soil. Considering the legal and environmental implications, this study aimed to diagnose and analyze the impacts of irregular urban settlement in the stream PPA two brothers in the city. Were technical visits, preparation of a checklist with key problems identified, survey
\end{abstract}


satellite images (CNES / Astrium Digital Globe). The images were georeferenced and processed in ArcGIS 9.3 software, which allowed the delimitation of the area of study and analysis of the state of degradation. Among the major observed impacts, is the destruction of riparian vegetation, which, added to other impacts are responsible for the degradation of $50.6 \%$ of APP at the top heal the stream, causing the disturbance of the ecosystem.

KEYWORDS: degradation, riparian forest, springs, recovery

\section{INTRODUÇÃO}

A intervenção humana vem afetando significativamente a disponibilidade e a qualidade hídricas em corpos d'água e reservas de água potável, contribuindo para acelerar o processo de degradação dos solos, assoreamento dos córregos, deterioração das matas ciliares e grande redução da biodiversidade (GIUNTI et al., 2014) .As áreas de Preservação Permanente (APP) têm função ambiental de preservar os recursos naturais, a biodiversidade, o fluxo gênico da fauna e flora, o solo e a segurança do bem-estar das populações humanas (FREITAS et al., 2013).

Atualmente a importância dos recursos hídricos e sua gestão, estão na pauta de debates de diferentes escalas de abrangência e localidades. No entanto, mais do que a preocupação com o abastecimento e consumo, deve ser em relação à condição em que se encontram as áreas onde nascem e percorrem estes recursos. A Área de Preservação Permanente do Córrego Dois Irmãos, situada na cidade de Gurupi, Tocantins, é importante na proteção deste corpo hídrico perene e valioso, mas fortemente antropizado.

A degradação da APP no alto curso do Córrego Dois Irmãos está associada ao avanço do processo de urbanização na cidade de Gurupi, marcado principalmente por ocupações irregulares que acabam gerando impactos diversos ao meio ambiente. Este processo de ocupação se torna um problema na medida em que provoca destruição das matas ciliares e a deterioração dos mananciais devido à utilização da água sem nenhum planejamento ambiental e/ou urbano. As microbacias, em especial, são um reflexo direto dessas atividades, uma vez que os córregos apresentam sinais claros da perturbação antrópica, destacando-se a eliminação de esgotos, rejeitos industriais, poluentes provenientes das atividades agrícolas, retirada da mata ciliar, entre outros (BAILLY et al., 2012).

Segundo SEBUSIANI \& BETTINE (2011), pela importância histórica e também pelo fato de hoje constituírem áreas de intensa ocupação urbana, as bacias hidrográficas presentes no meio urbano constituem um recorte espacial de importância fundamental para o planejamento urbano. Quase sempre, seu processo de uso e ocupação do solo, é desenvolvido de modo espontâneo, raramente fundamentado nas questões ambientais.

Trata-se, portanto, das condições ambientais da área de preservação do córrego Dois Irmãos, da bacia do Rio Santo Antônio, localizado no perímetro urbano da cidade de Gurupi, Tocantins. Os impactos causados por diversos fatores relacionados à produção e, por consequência, a produção do espaço, como o crescimento desordenado das cidades e a expansão do agronegócio, prejudicam e reduzem as áreas de cobertura florestal, incluindo as APP's. Estas podem ser consideradas um dos principais componentes de proteção aos recursos hídricos, onde sua ausência pode ocasionar erosão, esgotamento do solo, poluição dos rios e mananciais e perda da biodiversidade local. 
Observando a mudança na legislação, a alteração considerada também é relevante sobre a definição de nascente e olho d'água. Foi retirado o caráter de intermitência do conceito de nascente, mantendo-se somente para olho d'água, sendo definido como APP somente as áreas no entorno das nascentes e dos olhos d' água perenes, no raio mínimo de 50 m. A Lei n²12.651 de 25 de maio de 2012, que trata das normas gerais como fundamento central da proteção e uso sustentável das florestas e demais formas de vegetação nativa, não faz menção à proteção da bacia hidrográfica contribuinte. Tal detalhe é relevante, pois, a proteção adequada da área de recarga das nascentes é essencial e não deve ficar restrita ao seu entorno imediato (BRANCALION \& RODRIGUES, 2010).

Diante do contexto apresentado e das implicações legais e ambientais, este trabalho teve por objetivo diagnosticar e analisar os impactos decorrentes da ocupação urbana irregular na APP do córrego dois irmãos no Município de Gurupi, Tocantins, a partir da análise da evolução de ocupações irregulares entre 2004 a 2014.

\section{MATERIAL E MÉTODOS}

Córrego Dois Irmãos nasce nas proximidades do Parque Agropecuário da cidade de Gurupi-TO, cuja sede municipal possui as coordenadas 111043'45" S e 4904'07" W, percorre o bairro Jardim Tropical, onde há três represas, posteriormente passa pelo setor Trevo Oeste e por fim, deságua no córrego Pouso do Meio. Para este estudo, foi estabelecido um limite de análise para realização do diagnóstico ambiental da nascente principal até o limite com a rua Manual da Rocha, (Figura 01).

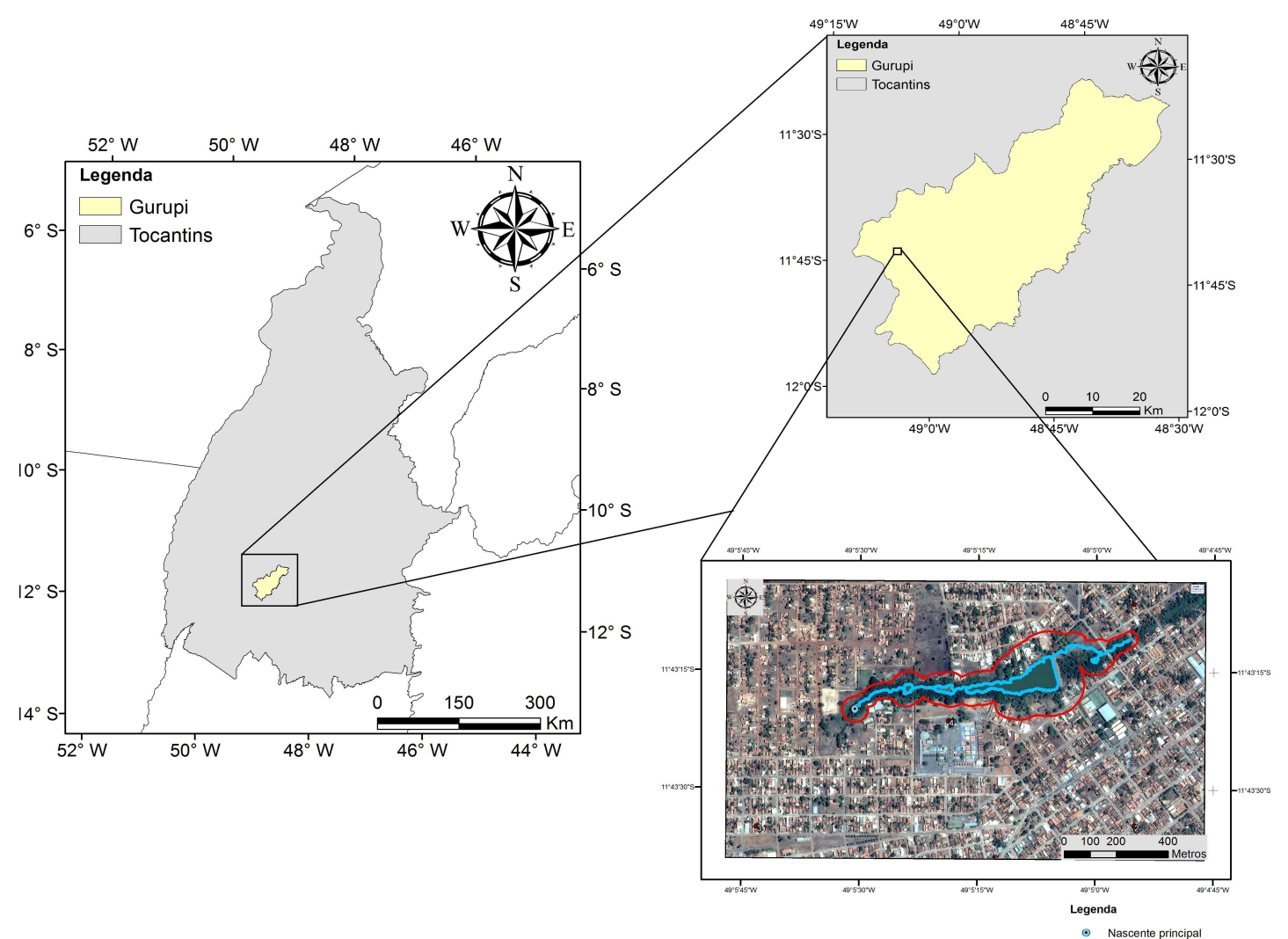

FIGURA 1 - Localização Geográfica da APP no alto curso do CórregơĐois Irmãos.

Fonte: autores (2015) 
A área estudada possui a classificação climática do C2wA'a' - Clima subúmido com moderada deficiência hídrica, com duas estações bem definidas, sendo um inverno seco e chuvas máximas no verão, (SEPLAN, 2013). É caracterizada pelo domínio da vegetação de Cerrado e é drenado pela bacia do Santo Antônio.

Considerando a Lei 12.651 de 25 de maio de 2012, o levantamento e caracterização dos problemas ambientais que ocorrem no Córrego Dois Irmãos por conta da ocupação ilegal na sua Área de Preservação Permanente, foram feitas através de visitas técnicas, no intuito de elaboração de um check-list com os principais problemas identificados, percorrendo a extensão do córrego, em torno do lago artificial, por suas margens e matas ciliares, situada entre os setores Jardim Tropical e Sol Nascente.

Segundo a Lei 12.651 de 25 de maio de 2012, as faixas marginais de qualquer curso d'água natural perene e intermitente, excluídos os efêmeros, desde a borda da calha do leito regular, em largura mínima de: largura;

a) 30 (trinta) metros, para os cursos d'água de menos de 10 (dez) metros de

b) 50 (cinquenta) metros, para os cursos d'água que tenham de 10 (dez) a 50 (cinquenta) metros de largura;

c) 100 (cem) metros, para os cursos d'água que tenham de 50 (cinquenta) a 200 (duzentos) metros de largura;

d) 200 (duzentos) metros, para os cursos d'água que tenham de 200 (duzentos) a 600 (seiscentos) metros de largura;

e) 500 (quinhentos) metros, para os cursos d'água que tenham largura superior a 600 (seiscentos) metros (BRASIL, 2012).

O município de Gurupi, em seu plano diretor, prevê a criação de um programa de desocupação das APP's invadidas e de recuperação de todos os ecossistemas degradados caracterizando o Córrego Dois Irmãos como uma das Áreas Especiais de Interesse Ambiental, definidas como sendo corredores naturais e com faixa de uso controlado, que preservará as nascentes e mananciais de rios, córregos e vertentes, incluídos os olhos d'água, preservando integralmente 0 ecossistema, a fauna, a flora e os recursos hídricos (GURUPI, 2007). No artigo 110, constam os objetivos específicos para esta Área Especial de Interesse Ambiental: I proibir e (ou) limitar o uso e a ocupação da Zona, em conformidade com a legislação vigente; II - preservar e (ou) conservar tais áreas visando a manter, com integridade ambiental, as nascentes, mananciais de rios, córregos e pequenas vertentes, preservando o ecossistema integral, a fauna, a flora e os recursos hídricos.

A área estudada está concentrada no alto curso do córrego supracitado, que vai da nascente até o maior lago artificial, inteiramente no setor Jardim Tropical e equivale a uma extensão de 16 ha, cerca de $42,1 \%$ da área total da APP.

Foram realizados levantamentos de imagens de satélites (Astrium Digital Globe), através do software Google Earth Pro, além da obtenção de uma série de imagens históricas de satélite no contexto temporal dos últimos 10 anos, em diferentes períodos com espaço de tempo de 5 anos de uma análise para outra, enquadrados entre os anos de 2004, 2009 e 2014. As imagens foram georreferenciadas e processadas no software ArqGis $10.2^{\circledR}$, o que permitiu a delimitação da área de estudo, que corresponde ao total da APP no alto curso do Córrego Dois Irmãos, bem como o total da área sob intervenção antrópica, além da 
delimitação da área de preservação em torno da nascente e das margens de acordo com a largura ao longo do córrego.

Para a avaliação dos aspectos e impactos ambientais observados na área de estudo foram estabelecidos os critérios descritos no quadro a seguir, adaptada de SANCHEZ (2008).

QUADRO 1 - Critérios adotados para avaliar a magnitude dos impactos observados na APP do alto curso do Córrego Dois Irmãos, Gurupi-TO.

\begin{tabular}{|c|c|c|}
\hline ASPECTOS & PARÂMETROS DE AVALIAÇÃO & $\begin{array}{l}\text { PONTUAÇÃO/ } \\
\text { SíMBOLOO }\end{array}$ \\
\hline $\begin{array}{l}\text { Efeito } \\
\text { (refere-se à qualidade ou } \\
\text { natureza do impacto) }\end{array}$ & $\begin{array}{l}\text { Positivo - A ação beneficia todas as partes ligadas } \\
\text { direta ou indiretamente à APP. } \\
\text { Negativo - Existe a possibilidade de ocorrer um } \\
\text { impacto de caráter significativo na APP. }\end{array}$ & $\mathbf{N}$ \\
\hline $\begin{array}{l}\text { Natureza } \\
\text { (produto de uma ação, } \\
\text { levando em } \\
\text { consideração os efeitos } \\
\text { que o impacto apontado } \\
\text { possa ocasionar no }\end{array}$ & $\begin{array}{l}\text { Direto - A ação atinge a área de influência do } \\
\text { empreendimento, ou seja, dentro dos limites da } \\
\text { APP. } \\
\text { Indireto - O impacto vai além do entorno da APP. }\end{array}$ & D \\
\hline $\begin{array}{l}\text { Dinâmica } \\
\text { (refere-se à duração e } \\
\text { periodicidade do } \\
\text { impacto) }\end{array}$ & $\begin{array}{l}\text { Temporário - O impacto cessa logo após a ação } \\
\text { impactante; } \\
\text { Permanente - O impacto perdura por um tempo, } \\
\text { mesmo após o término da ação; }\end{array}$ & $\mathbf{T}$ \\
\hline & Cíclico - A ação apresenta uma sazonalidade. & C \\
\hline $\begin{array}{l}\text { Duração } \\
\text { (corresponde ao tempo } \\
\text { que a ação impactante }\end{array}$ & $\begin{array}{l}\text { Curto - A ação permanece num curto espaço de } \\
\text { tempo; }\end{array}$ & C \\
\hline $\begin{array}{l}\text { permanece no meio, } \\
\text { mesmo após cessada a } \\
\text { ação). }\end{array}$ & $\begin{array}{l}\text { Médio - A ação pode ser cessada após um tempo; } \\
\text { Longo - O impacto pode ser considerado } \\
\text { irreversível. }\end{array}$ & M \\
\hline $\begin{array}{l}\text { Plástica } \\
\text { (refere-se ao dinamismo } \\
\text { do impacto) }\end{array}$ & $\begin{array}{l}\text { Reversível - O local pode voltar a ter a paisagem } \\
\text { original. } \\
\text { Irreversível- Após a ação impactante, mesmo com } \\
\text { medidas mitigadoras, o local não volta a ter a } \\
\text { paisagem original. }\end{array}$ & $\mathbf{R}$ \\
\hline \multirow[t]{2}{*}{$\begin{array}{l}\text { Magnitude } \\
\text { (refere-se à grandeza do } \\
\text { impacto em termos } \\
\text { absolutos. }\end{array}$} & $\begin{array}{l}\text { Pequena - O meio permanece inalterado; } \\
\text { Média - O meio apresenta uma leve alteração } \\
\text { quanto à sua paisagem, porém de forma } \\
\text { inexpressiva; } \\
\text { Grande - A ação altera toda a paisagem. }\end{array}$ & 3 \\
\hline & & Continua... \\
\hline
\end{tabular}




\begin{tabular}{|c|c|c|}
\hline ASPECTOS & PARÂMETROS DE AVALIAÇÃO & $\begin{array}{l}\text { PONTUAÇÃO/ } \\
\text { SÍMBOLO }\end{array}$ \\
\hline \multirow{3}{*}{$\begin{array}{l}\text { Espaço } \\
\text { (refere-se à abrangência } \\
\text { espacial do impacto) }\end{array}$} & $\begin{array}{l}\text { Local - A ação ocorre em uma área pequena, não } \\
\text { ocasionando risco de espalhar; }\end{array}$ & 1 \\
\hline & $\begin{array}{l}\text { Regional - O impacto estende-se por uma área um } \\
\text { pouco maior, em geral, no entorno do } \\
\text { empreendimento; }\end{array}$ & 2 \\
\hline & $\begin{array}{l}\text { Global - A ação não tem controle afetando assim } \\
\text { outras regiões. }\end{array}$ & 3 \\
\hline \multirow{3}{*}{$\begin{array}{c}\text { Frequência } \\
\text { (corresponde a } \\
\text { quantidade de vezes que } \\
\text { determinada ação pode } \\
\text { ocorrer.) }\end{array}$} & Baixa - Probabilidade da ação ocorrer é pequena; & 1 \\
\hline & $\begin{array}{l}\text { Média - Quantidade de vezes que o impacto } \\
\text { ocorre. Apresenta uma ocorrência considerável; } \\
\text { Alta -Ação impactante repetida várias vezes. }\end{array}$ & $\begin{array}{l}2 \\
3\end{array}$ \\
\hline & $\begin{array}{l}\text { Não Significativa - O impacto provocado não } \\
\text { altera a qualidade de vida do meio ou do homem. }\end{array}$ & 1 a 3 \\
\hline \multirow{2}{*}{$\begin{array}{l}\text { Significância } \\
\text { (resultado do produto } \\
\text { entre a Magnitude } x \\
\text { Abrangência } x \\
\text { Frequência) }\end{array}$} & $\begin{array}{l}\text { Moderada - A área lesionada pela ação, quando } \\
\text { negativa, pode ser recuperada e quando positiva, } \\
\text { apresenta uma melhoria razoável na qualidade de } \\
\text { vida. }\end{array}$ & 4 a 6 \\
\hline & $\begin{array}{l}\text { Significativa - A ação impactante apresenta uma } \\
\text { significativa evoluça benéfica ao meio ambiente, } \\
\text { quando positiva, e uma perda na qualidade de vida } \\
\text { quando negativa. }\end{array}$ & 7 a 9 \\
\hline
\end{tabular}

Fonte: Adaptado de SANCHES, 2008.

Para que o diagnóstico ambiental na área de estudo fosse realizado, foram consideradas as informações do quadro 1, para avaliação dos principais impactos observados. Inicialmente foram identificados os aspectos, ou seja, as ações do homem que podem influenciar o meio, em seguida, os impactos ocasionados. Posteriormente foram feitas as pontuações de acordo com os critérios préestabelecidos e adaptados.

\section{RESULTADOS E DISCUSSÃO}

Considerando a área da APP do Córrego Dois Irmãos em Gurupi encontra-se fortemente antropizada, sendo 8,1 ha de área degradada, o que corresponde a um total de $50,6 \%$ da APP no alto curso do Córrego Dois Irmãos principalmente no seu alto curso, com construções de áreas de lazer que invadem inclusive o leito do lago artificial e edificações irregularmente construídas na área, que deveria ser destinada à preservação. (Figura 2). A partir de análises de campo e com auxílio de imagens de satélites, observou-se que uma série de vias públicas foi obstruída por construções irregulares. 


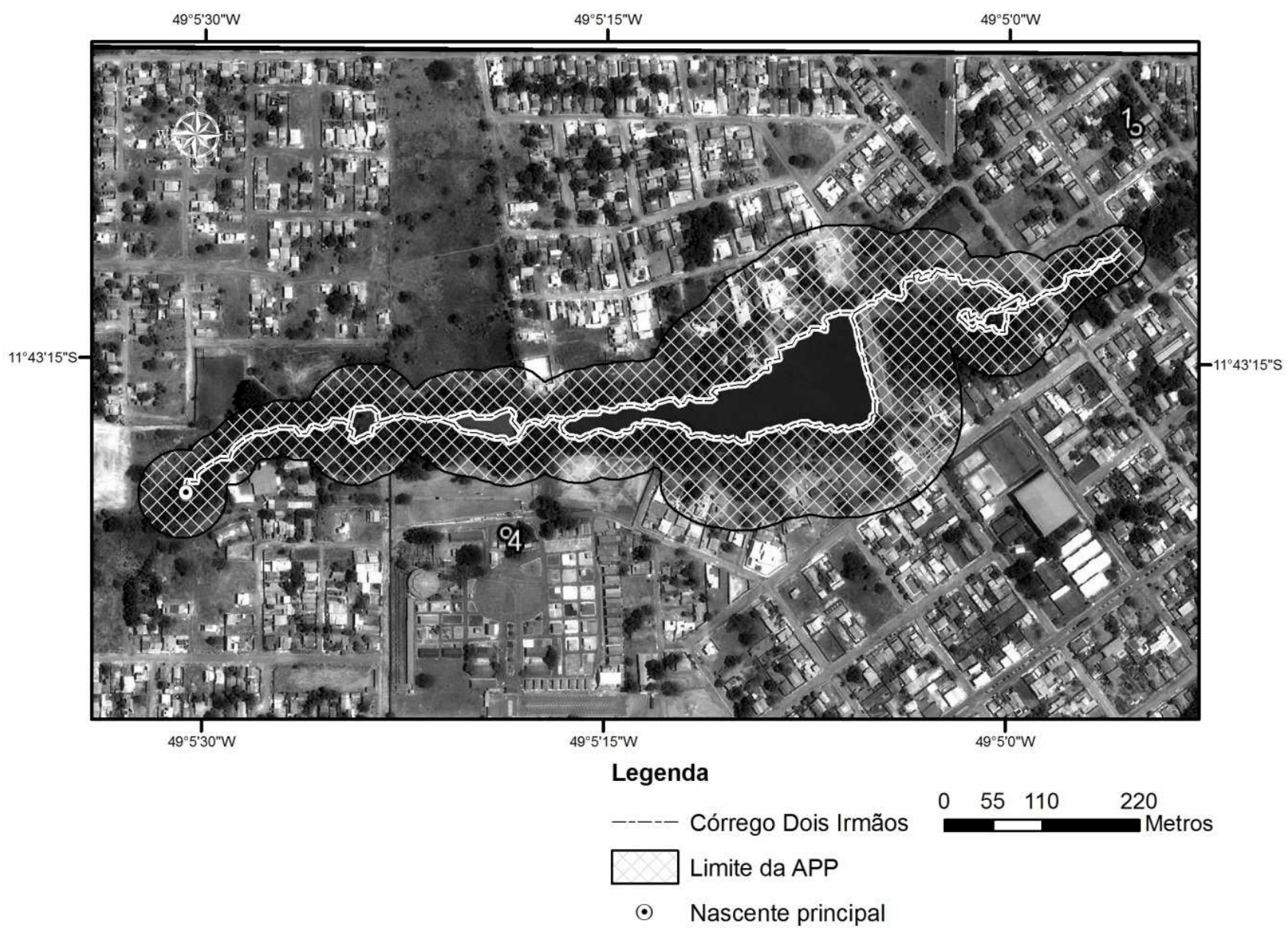

FIGURA 2 - APP no Alto Curso do Córrego Dois Irmãos em Gurupi-TO Fonte: autores (2015)

$\mathrm{Na}$ área estudada, foram observadas diversas ações impactantes como a destruição das matas ciliares, erosão do solo, assoreamento do corpo hídrico e construção de edificações irregulares, que contribuíram principalmente para uma drástica redução da cobertura das matas ciliares, bem como outros impactos ambientais registrados em um Check-List, como a destruição das matas ciliares, erosão do solo, assoreamento do corpo hídrico, construção de edificações irregulares e compactação do solo.

Além da retirada da cobertura vegetal, que determina a redução dos índices de umidade atmosférica e desequilíbrios no ecossistema, outros impactos diagnosticados neste estudo, como a exposição do solo, que contribui diretamente para os processos de erosão e compactação; assoreamento, uma vez que o solo exposto sob a ação dos agentes intempéricos se desagrega com facilidade e é depositado no leito do córrego; construções de edificações em área irregular, o que determina a retirada de mata ciliar provocando desestruturação do ecossistema ripário (LIMA \& ZAKIA , 2006).

Foi possível observar nas imagens, a evolução da degradação das matas ciliares desde 2004, caracterizando preocupante degradação da vegetação até o ano de 2014. Esta degradação caracteriza-se pela retirada da cobertura vegetal para construção de edificações, o que acarreta impactos secundários como a formações de erosões laminares, assoreamento do corpo hídrico.

Considerando a área de estudo, somados os valores da intervenção antrópica nas matas ciliares e nas mediações da nascente, totaliza-se 8,1 ha de ENCICLOPÉDIA BIOSFERA, Centro Científico Conhecer - Goiânia, v.13 n.23; p. 4762016 
área degradada, o que corresponde a um total de $50,6 \%$ da APP no alto curso do Córrego Dois Irmãos (Figura 03).

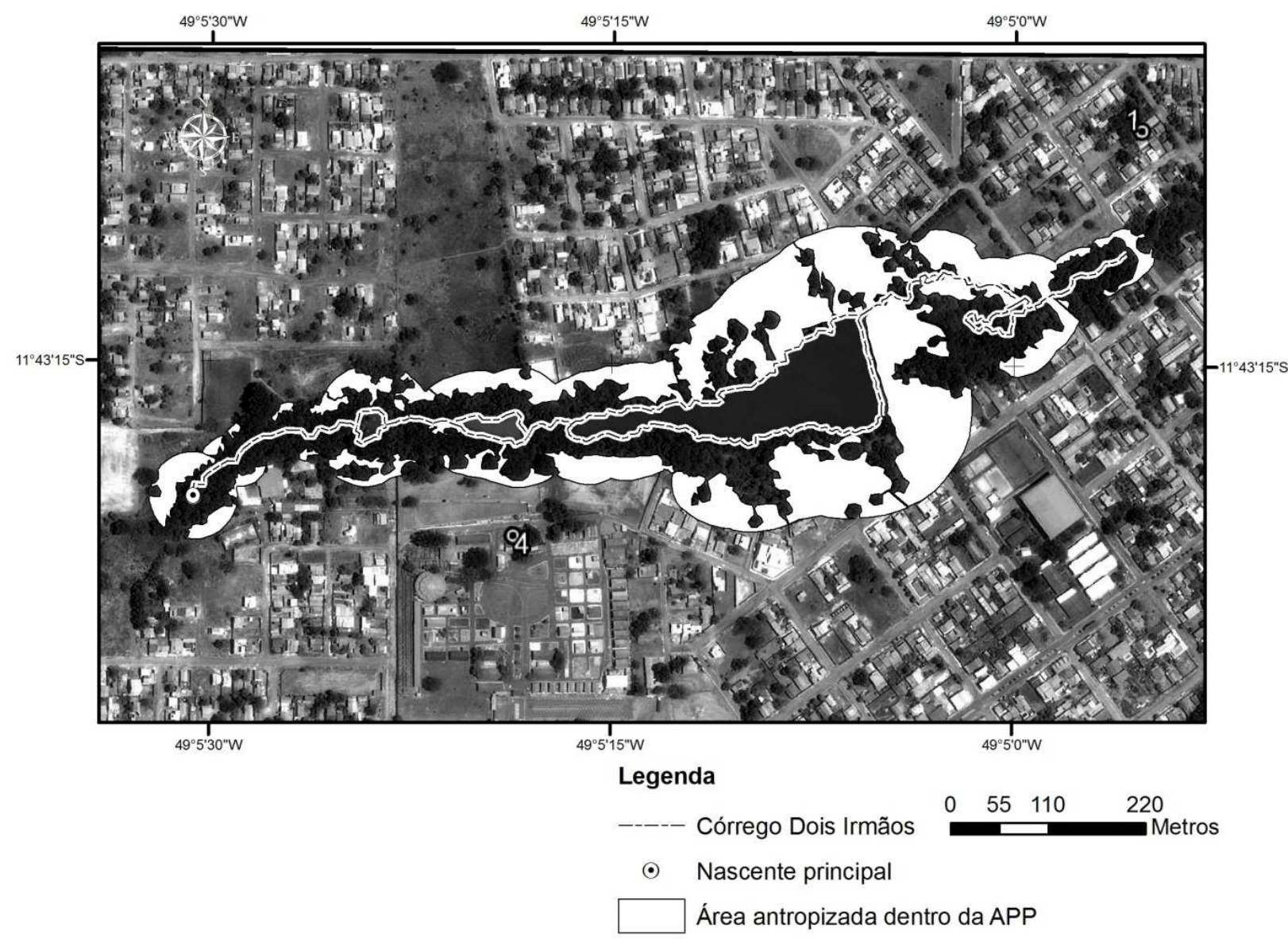

FIGURA 3 - Área antropizada da APP no Alto Curso do Córrego Dois Irmãos, 2014.

Fonte: autores (2015)

O principal impacto ambiental na área estudada foi a retirada da mata ciliar que, segundo ATTANASIO et al. (2006), desempenham papéis ecológicos vitais, principalmente em relação à qualidade e a quantidade da água dos rios, dos córregos e dos ribeirões que compõem as bacias hidrográficas, por expor ao mesmo tempo o solo e o corpo hídrico, acarretando no assoreamento deste recurso, principalmente nos meses mais chuvosos do ano.

Dada a importância que as matas ciliares exercem na manutenção dos ecossistemas, principalmente nas áreas urbanas, é necessário que haja a preocupação com o seu estado de conservação. É preciso uma avaliação dos métodos de recuperação da mata ciliar, cuja importância reside na função protetora que a mesma exerce sobre os recursos hídricos e a biodiversidade, que segundo ZANZARINI \& ROSOLEN (2008), têm importância fundamental na manutenção das nascentes e da qualidade da água dos mananciais. A partir análise da matriz de interação (quadro 2), faz-se necessária a recuperação da mata ciliar, que no cerrado, pode ser realizada de forma conjunta, adotando técnicas de regeneração natural, por ser um método mais econômico para restauração de ambientes degradados. Isso por que na condução da regeneração natural, o uso da mão-deENCICLOPÉDIA BIOSFERA, Centro Científico Conhecer - Goiânia, v.13 n.23; p. 4772016 
obra é menor em comparação com as outras técnicas de recuperação, podendo dessa forma reduzir significativamente 0 custo na recuperação das áreas perturbadas, principalmente áreas de médio e grande porte (RIBEIRO, 2013).

QUADRO 2 - Matriz de interação - Avaliação dos parâmetros ambientais observados na área de preservação permanente Córrego Dois Irmãos em GurupiTO.

\begin{tabular}{|c|c|c|c|c|c|c|c|c|c|c|c|}
\hline \multicolumn{12}{|c|}{ Avaliação de Aspectos e Impactos Ambientais } \\
\hline $\begin{array}{c}\text { Ação } \\
\text { Impactante }\end{array}$ & Impacto & $\frac{0}{\frac{0}{0}}$ & $\begin{array}{l}\frac{\varepsilon}{d} \\
\text { o } \\
\text { o }\end{array}$ & $\begin{array}{l}\frac{0}{0} \\
\frac{\pi}{0} \\
\frac{0}{\pi} \\
\frac{\pi}{0} \\
\frac{0}{\varepsilon} \\
\stackrel{0}{0}\end{array}$ & 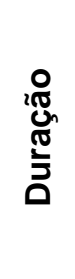 & 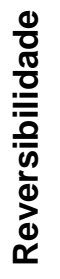 & 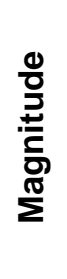 & 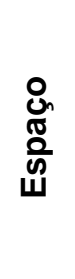 & 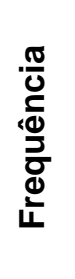 & 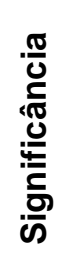 & $\begin{array}{l}\text { Medidas } \\
\text { Mitigadoras }\end{array}$ \\
\hline $\begin{array}{c}\text { Retirada da } \\
\text { Cobertura } \\
\text { Vegetal }\end{array}$ & $\begin{array}{c}\text { Redução da } \\
\text { umidade } \\
\text { atmosférica; } \\
\text { desequilíbrio no } \\
\text { ecossistema. }\end{array}$ & $\mathrm{N}$ & $\mathrm{D}$ & $P$ & M & $\mathrm{R}$ & 2 & 1 & 2 & 4 & $\begin{array}{c}\text { Elaboração de um } \\
\text { programa de } \\
\text { recuperação da } \\
\text { vegetação } \\
\text { degradada. }\end{array}$ \\
\hline $\begin{array}{c}\text { Exposição } \\
\text { do } \\
\text { Solo }\end{array}$ & Erosão do solo & $\mathrm{N}$ & 1 & $\mathrm{P}$ & M & $\mathrm{R}$ & 2 & 1 & 2 & 6 & $\begin{array}{c}\text { Criação de uma } \\
\text { área de proteção } \\
\text { permanente na } \\
\text { área de vegetação } \\
\text { ciliar. }\end{array}$ \\
\hline $\begin{array}{l}\text { Assoreame } \\
\text { nto dos } \\
\text { corpos } \\
\text { hídricos }\end{array}$ & $\begin{array}{c}\text { Deposição de } \\
\text { partículas sólidas } \\
\text { no corpo hídrico } \\
\text { próximo. }\end{array}$ & $\mathrm{N}$ & 1 & $\mathrm{P}$ & L & $\mathrm{R}$ & 2 & 1 & 3 & 6 & $\begin{array}{l}\text { Isolamento e } \\
\text { vegetação das } \\
\text { margens do } \\
\text { córrego afetadas. }\end{array}$ \\
\hline $\begin{array}{l}\text { Construção } \\
\text { de } \\
\text { edificações } \\
\text { irregulares } \\
\text { na área da } \\
\text { APP }\end{array}$ & $\begin{array}{c}\text { Perda da } \\
\text { vegetação ciliar, } \\
\text { desestruturação } \\
\text { do ecossistema } \\
\text { ripário }\end{array}$ & $\mathrm{N}$ & $\mathrm{D}$ & $P$ & M & $\mathrm{R}$ & 2 & 1 & 2 & 5 & $\begin{array}{l}\text { Emitir parecer } \\
\text { técnico aos órgãos } \\
\text { responsáveis para } \\
\text { aplicação da } \\
\text { legislação. }\end{array}$ \\
\hline
\end{tabular}

Fonte: Adaptado de SANCHES, 2008.

A Área de Preservação Permanente do Córrego Dois Irmãos possui uma área total de 38 ha, sendo 7.34 ha de área degradada, o que corresponde a $19.31 \%$ do total da APP (RIBEIRO, 2013). Ressalta-se que esta degradação consiste principalmente no desmatamento para construção de edificações comerciais e residenciais, em sua maior parte, em área irregular. A princípio, o total da área degradada pode parecer relativamente baixo, no entanto, deve-se considerar o nível de impacto que ela representa em se tratando de um manancial importante no contexto hidrográfico do município. 
Considerando a vegetação remanescente (Figura 02) na área estudada, a técnica de regeneração natural pode ser uma alternativa já que apresenta condições favoráveis para o desenvolvimento natural da vegetação, apesar do baixo custo e de fácil realização, possui a característica de ser um processo bastante lento. Segundo BOTELHO (2003) projetos de recuperação de área degradada, visando à proteção do solo e do curso d'água, ondes e deseja um resultado em curto prazo, é aconselhável que se use outros métodos de recuperação que venha acelerar a sucessão da vegetação.

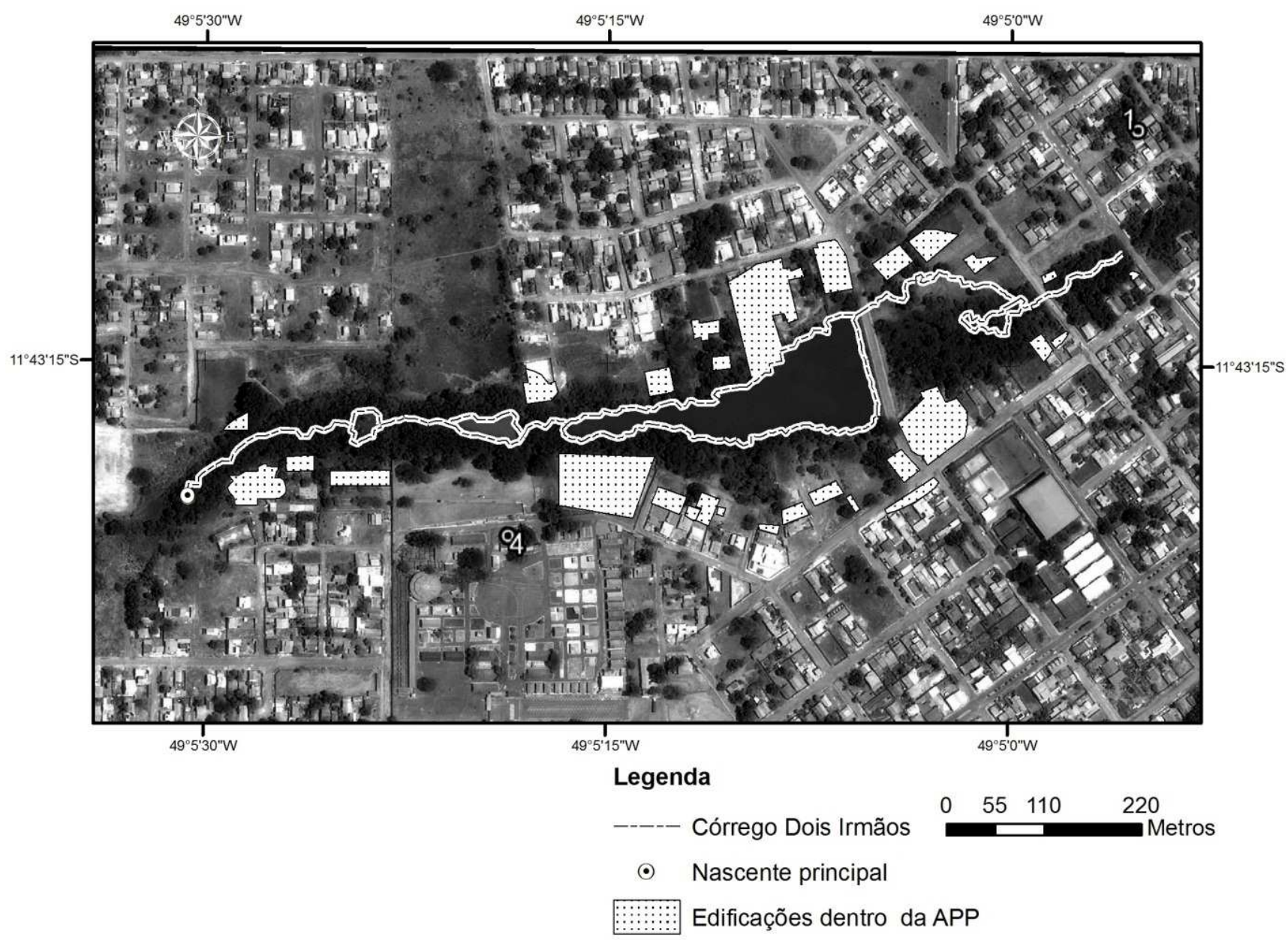

FIGURA 4 - Edificações irregulares no perímetro da APP no alto curso do Córrego Dois Irmãos.

Fonte: autores (2015)

Observou-se a construção de edificações dentro da área de preservação (Figura 04) em desrespeito aos limites das APP's impostas pelo novo Código Florestal, (BRASIL,2012). Estas construções têm impactado de forma negativa as margens do córrego, com a retirada da mata ciliar potencializando os riscos de assoreamento, podem ainda, ao longo do tempo, contribuir para a perda gradual e desequilíbrio do ecossistema, afetando principalmente o corpo hídrico, que abastece a comunidade local.

Em outra análise, foram elencadas cinco vias públicas de acesso (sentido NNW-ESE), obstruídas pela construção de edificações irregulares. A compreensão deste processo de fechamento de vias púbicas pode ser entendida dividindo-os em ENCICLOPÉDIA BIOSFERA, Centro Científico Conhecer - Goiânia, v.13 n.23; p. 4792016 
dois grupos: o primeiro grupo compreende as ruas interditadas por um mesmo proprietário de imóveis nos dois lados da via que se inicia na Av. L, sentido W-E, (Figura 5), na parte superior. Assim, tornou-se prática comum a obstrução de vias públicas por proprietários de imóveis que as margeiam e que chegaram ao local num período de tempo mais antigo.

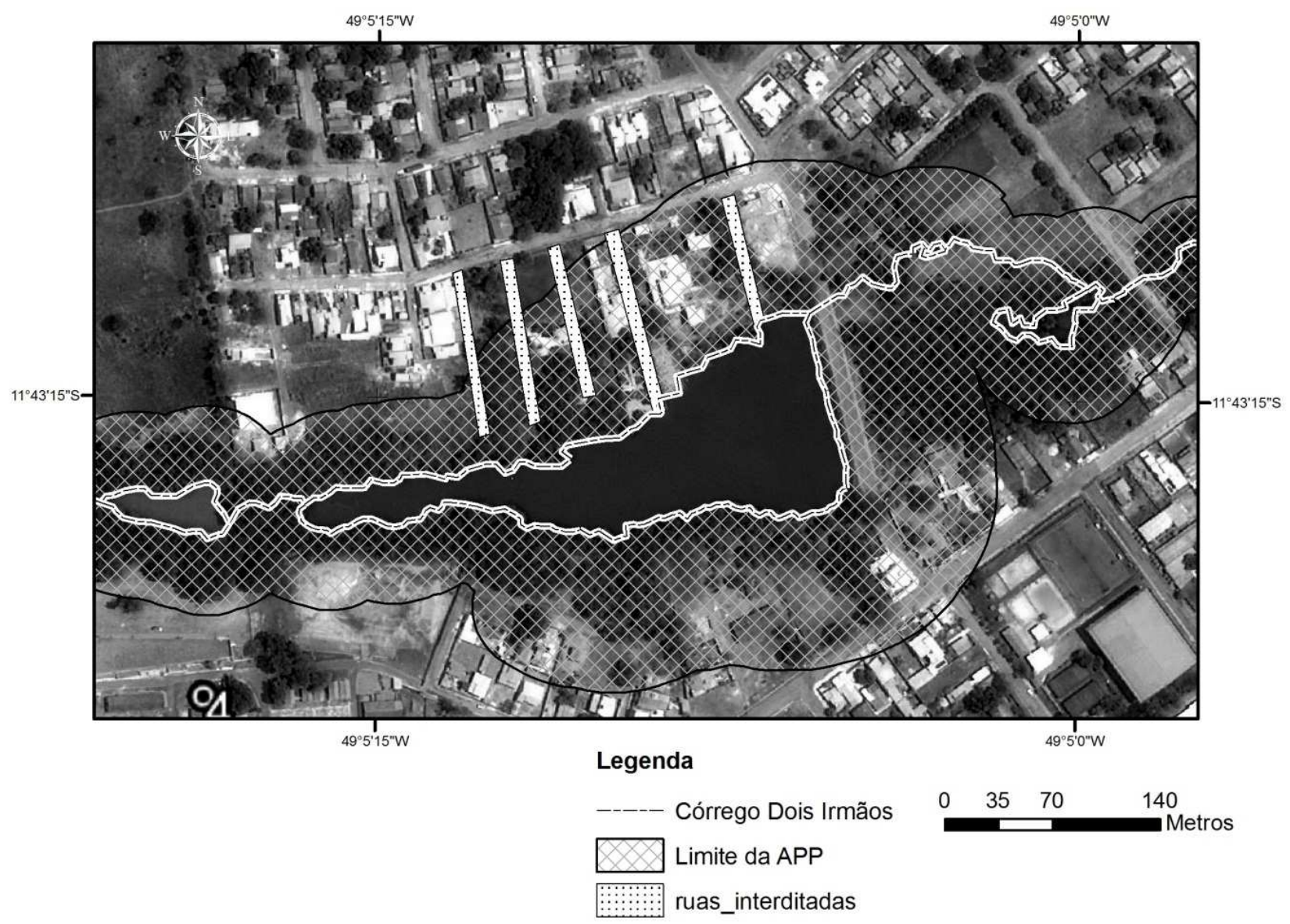

FIGURA 5 - Obstrução de vias públicas por construções irregulares na APP do Córrego Dois Irmãos, em Gurupi-TO.

Fonte: autores (2015)

Observa-se também, proprietários de imóveis, que chegaram ao local nos últimos três anos e adquiriram lotes à direita da via pública, iniciando o fechamento da via com a construção de muros, tornando-as extensões dos seus quintais. No entorno do lago artificial na Área de Preservação Permanente do Córrego Dois Irmãos, observou-se um considerável avanço da degradação da mata ciliar ao longo dos últimos 10 anos, em função das atividades antrópicas.

A supressão da mata ciliar pelo avanço das edificações não obedece às determinações do Novo Código Florestal Brasileiro, que estabelece uma distância mínima de preservação em relação aos córregos e nascentes. O cenário encontrado na APP do córrego em questão é caracterizado por edificações irregulares que invadem até mesmo o leito do córrego, contribuindo para a erosão do solo e o assoreamento do corpo hídrico. 
A aquisição de lotes paralelos por um mesmo proprietário facilita o fechamento das vias públicas que dariam acesso ao lago, impedindo o poder público de realizar a fiscalização necessária para conter o avanço da degradação que ocorre desde a captação da água sem autorização dos órgãos competentes até a construção de áreas de lazer.

Segundo o então Secretário de Meio Ambiente do município, existe uma proposta de lei na Assembleia Legislativa que visa o aumento da área de preservação do lago, que acarretaria na retirada de toda e qualquer edificação em suas mediações. No entanto, nem o que existe hoje é respeitado, transparecendo ideia de que a ocupação irregular, a degradação das matas ciliares e apropriação de recursos hídricos por parte de pessoas com alto poder aquisitivo não estão sujeitos à aplicação da lei.

Ao longo do tempo, boa parte da cobertura vegetal foi gradativamente retirada pela intervenção antrópica. No ano de 2004, a área total de vegetação era de 5,9 ha (Figura 6).

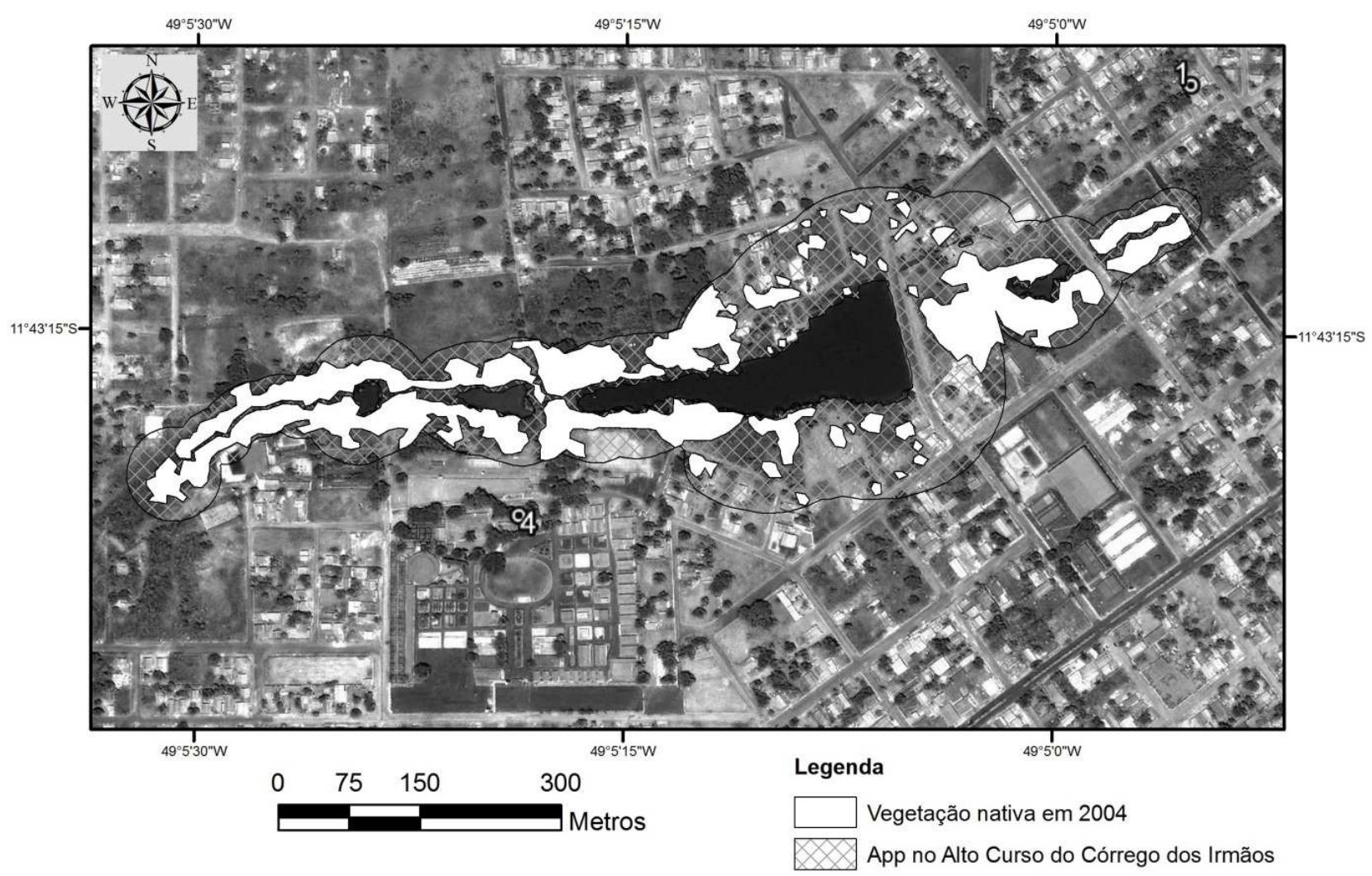

FIGURA 6 - Cobertura vegetal no entorno do alto curso do Córrego Dois Irmãos em 2004.

Fonte: autores (2015)

A partir da análise da imagem, observa-se que as edificações irregulares mais agressivas ao meio ambiente já estavam presentes no ano de 2004, no entanto, uma área considerável de vegetação ciliar encontrava-se preservada. 
Ao contrário do que se esperava, a cobertura vegetal no entorno da APP no alto curso do Córrego Dois Irmãos, no ano de 2009, aumentou para 6,8 ha, uma proporção de $13,23 \%$ em relação ao total verificado no ano de 2004 , fato que contou com menor intensidade das intervenções antrópicas, permitindo uma recuperação da vegetação a partir da regeneração natural (Figura 7).

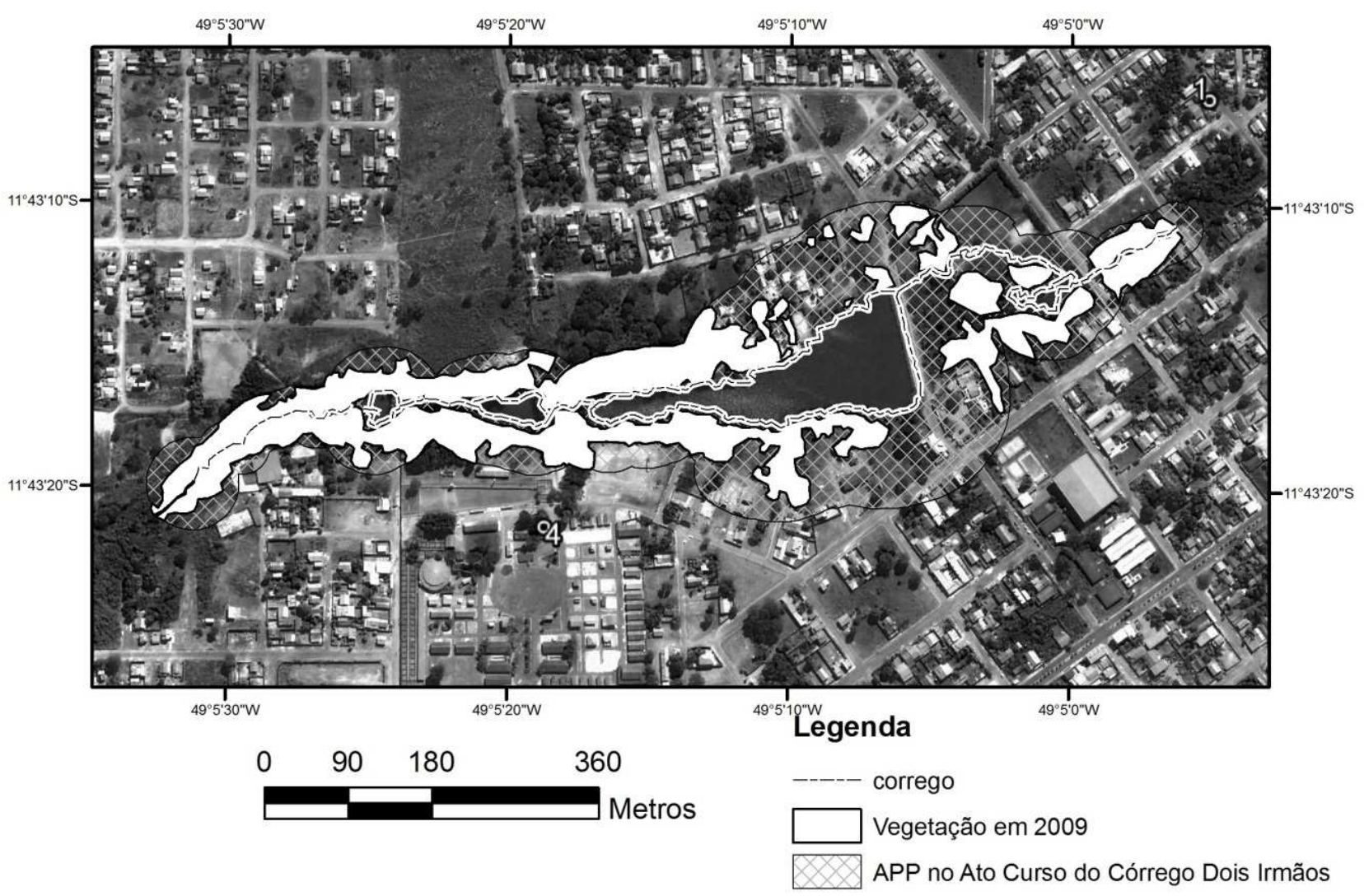

FIGURA 7 - Cobertura vegetal no entorno do alto curso do Córrego Dois Irmãos, 2009

Fonte: autores (2015)

Tomando como referência os valores iniciais de 2004. Observou-se um aumento da cobertura vegetal de 5,9 ha, registrados em 2004 para 6,6 ha em 2014, ou seja, um pequeno aumento de 3\% da cobertura vegetal identificada em 2004 (Figura 8). Este aumento está relacionado à enorme resiliência do bioma cerrado, além da regeneração natural da mata ciliar no alto curso da APP do córrego Dois Irmãos em Gurupi-TO. Segundo RIBEIRO et al. (2012), por meio da regeneração natural, as matas ciliares apresentam capacidade de se recuperarem de distúrbios naturais e antrópicos.

$\mathrm{Na}$ área de estudo também foi observado intenso escoamento superficial, principalmente nos meses mais chuvosos. Tal aumento é associado à impermeabilização do solo dentro das mediações da APP. Segundo RODRIGUES et al. (2015), por meio da impermeabilização do solo, que ocorrem nas áreas urbanas (construções, telhados, estacionamentos, ruas asfaltadas, entre outros) ocorre a redução da infiltração da água de chuva com consequente aumento do volume de escoamento de água na superfície do terreno. Com isso, ocorre o carreamento das partículas do solo e compromete a qualidade da água, tanto no ambiente urbano 
quanto no rural, provocando assim o processo de erosão do solo e assoreamento do leito do córrego.

Entretanto, devido à pequena declividade do relevo, na área de estudo foram observadas apenas erosões laminares e assoreamento do corpo hídrico de média magnitude, em que o meio apresenta uma leve alteração quanto à sua paisagem, porém de forma inexpressiva.

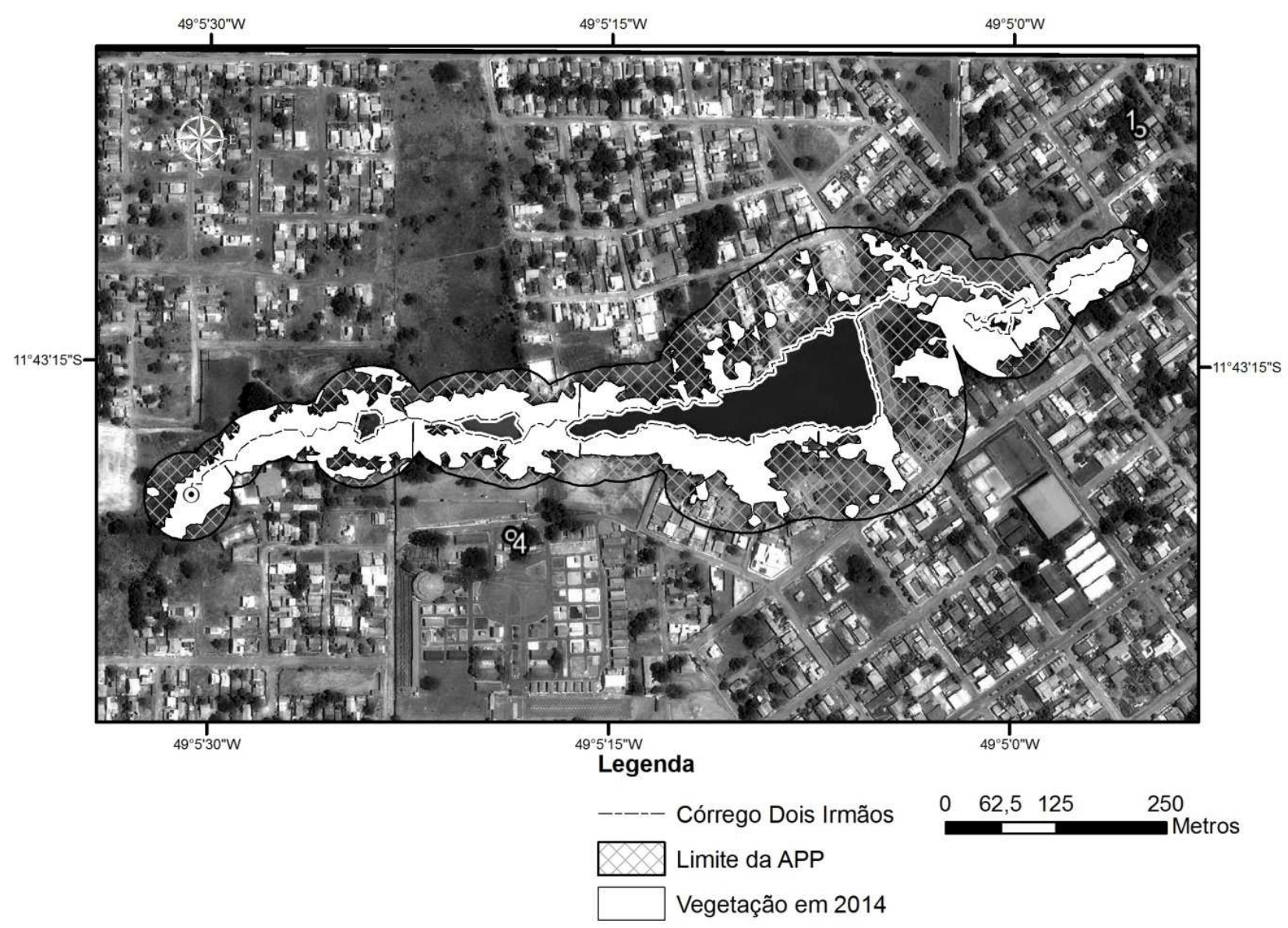

FIGURA 8 - Cobertura vegetal no entorno do alto curso do Córrego Dois Irmãos, 2014

Fonte: autores (2015)

Com o avanço da malha urbana e do crescimento da atividade da construção civil, pode-se observar pela evolução mostrada nas imagens que a maior parte da cobertura vegetal degradada encontra-se nos limites da área preservação permanente, o que contribuiu drasticamente para a degradação da cobertura vegetal, podendo comprometer o recurso hídrico em um futuro próximo.

$\mathrm{Em}$ estudos realizados em vales no perímetro urbano de Londrina-PR, TRABAQUINI et al. (2009), observaram que somente $26,25 \%$ de APPs presente nos fundos de vale são ocupadas pela classe Florestal, esta classe deveria representar a maioria das áreas de fundo de vale. Mas, esta realidade pode ser explicada pelo intenso processo de urbanização que ocorreu nos últimos anos. 
O desrespeito e o desinteresse pela preservação das APPs também foi observado em estudos realizados no sudoeste goiano. As APP's mesmo apresentando diversas funções importantes relacionadas a conservação da biodiversidade e conservação dos cursos hídricos estão pouco conservadas nos dois municípios, sendo reflexo das atividades socioeconômicas no Sudoeste Goiano. Apenas 20,13\% das APP's de Jataí encontram-se preservadas, já para o município de Rio Verde apenas 16,34\%, demonstrando o descaso com as leis e preocupação com o meio ambiente na região (TSUJII et al., 2014).

Embora a proteção das APPs seja reconhecidamente importante, o que se observa é a gradativa ocupação destas áreas por empreendimentos irregulares, construídos a partir de brechas legais. O novo Código Florestal reconhece a ineficiência do poder público no controle do ordenamento urbano e, no lugar de estabelecer mecanismos que promovam a recuperação das APPs, apresenta o que se pode chamar de "gambiarras" jurídicas para consumar a degradação (AZEVEDO \& OLIVEIRA, 2014).

Deve-se entender as APPs em sua importância plena, não só para manutenção ambiental e social como econômica. Segundo SILVA-NETO et al. (2013), a manutenção do meio ambiente ecologicamente equilibrado é financeiramente mais econômica do que a recuperação/restauração de áreas degradadas. As APP's que foram ocupadas irregularmente devem ser desocupadas e recuperadas ao estado de conservação original. Tanto o processo de desocupação dos moradores irregular quanto recuperação da área envolvem custos elevados.

\section{CONCLUSÕES}

O principal impacto ambiental diagnosticado foi a retirada da cobertura vegetal no alto curso do Córrego Dois Irmãos. Considerando a área de estudo, somados os valores da intervenção antrópica nas matas ciliares e nas mediações da nascente, totaliza-se 8,1 ha de área degradada, o que corresponde a um total de $50,6 \%$ da APP no alto curso do Córrego Dois Irmãos.

A cobertura vegetal nos últimos dez anos (2004-2014) manteve-se estável, com aumento de 3\% em 2014 em relação ao início das análises em 2004, demonstrando boa capacidade do ecossistema de regenerar-se, mesmo com a forte influência antrópica.

\section{REFERÊNCIAS}

ATTANASIO, C.; RODRIGUES, R. R.; GANDOLFI, S.; NAVE, A. Adequação ambiental de propriedades rurais recuperação de áreas degradadas restauração de matas ciliares. In: Apostila de Recuperação. Universidade de São Paulo, Escola Superior de Agricultura "Luiz de Queiros". Departamento de Ciências Biológicas. Laboratório de ecologia e restauração floresta. Piracicaba-SP: Universidade de São Paulo, 2006. 63 p.

AZEVEDO, R. E. S. D.; OLIVEIRA, V. P. V. D. Reflexos do novo Código Florestal nas Áreas de Preservação Permanente - APPs - urbanas. DEMA Desenvolvimento e Meio Ambiente, v. 29, n. 2, p. 71-91, 2014. Disponível em: < http://dx.doi.org/10.5380/dma.v29i0.32381 > doi: 10.5380/dma.v29i0.32381 
BAILLY, D.; FERNANDES, C. A.; SILVA, V. F. B.; KASHIWAQUI, E. A. L.; DAMÁSIO, J. F. et al. Diagnóstico ambiental e impactos sobre a vegetação ciliar da microbacia do córrego da Ponte, Área de proteção ambiental do rio Iguatemi, MS. Revista em Agronegócio e Meio Ambiente, v. 5, n. 2, 2012. ISSN 2176-9168. Disponível em:

http://periodicos.unicesumar.edu.br/index.php/rama/article/view/1680/1665 >

BOTELHO, S. Princípios e métodos silviculturais. Lavras-MG: UFLA, 2003. 144 p.

BRANCALION, P. H. S.; RODRIGUES, R. R. Implicações do cumprimento do Código Florestal vigente na redução de áreas agrícolas: um estudo de caso da produção canavieira no Estado de São Paulo. Biota Neotropical, v. 10, n. 4, p. 6366 , 2010.

Disponível em: http://www.biotaneotropica.org.br/v10n4/pt/fullpaper?bn01010042010+pt >

BRASIL. Código Florestal. Lei n¹2.651 de 25 de maio, 2012. Disponível em: < http://www.planalto.gov.br/ccivil 03/ ato2011-2014/2012/lei//12651.htm > Acesso em 05 de Agosto de 2015

FREITAS, E. P.; DE MORAES, J. F.; PECHE FILHO, A.; STORINO, M. Indicadores ambientais para áreas de preservação permanente. Revista Brasileira de Engenharia Agrícola e Ambiental, Campina Grande, v. 17, n. 4, p. 443-449, 2013. Disponível em: < http://www.agriambi.com.br/revista/v17n04/v17n04a13.pdf > DOI: $10.1590 / S 1415-43662013000400013$

GIUNTI, O. D.; DE SÁ, E. B. R.; DE OLIVEIRA, T. C.; SILVA, A. V. Análise e Diagnóstico Ambiental: Adequações ao Novo Código Florestal - um Estudo de Caso. Revista Agrogeoambiental, n. 2, p. 33-39, 2014. Disponível em: < https://www.agrogeoambiental.ifsuldeminas.edu.br/index.php/Agrogeoambiental/artic le/view/746/587 > DOI: 10.18406/2316-1817v0n02014746

GOOGLE EARTH, 2015. Imagens, Disponível em: < http://www.earth.google.com > Acesso em: 12 de julho de 2015

LIMA, W. P.; ZAKIA, M. J. B. O papel do ecossistema ripário. In. As florestas plantadas e a água. Implementando o conceito da microbacia hidrográfica como unidade de planejamento. São Paulo: RiMa, 2006. p.77-88.

RIBEIRO, H. F. Caracterização das App's dos Córregos Inseridos no Perímetro Urbano da Cidade de Gurupi-TO. In: 9ํㅗㄴ Seminário de Iniciação Científica da UFT, v. 5, 2013.

RODRIGUES, A. J.; PEREIRA, M. A.; MARTINS, I. C. D. M.; SOUZA4., P. A. D. Diagnóstico Ambiental de um Trecho da Área de Preservação Permanente (APP), Margens do Córrego Pouso do Meio, em Gurupi-TO. Enciclopédia Biosfera, v. 11, n. 21, p. 3103-3113, 2015. Disponível em: < http://www.conhecer.org.br/enciclop/2015b/multidisciplinar/Diagnostico\%20ambiental \%20de\%20um\%20trecho.pdf > 
SANCHEZ, L. E. Avaliação de impacto ambiental: conceitos e métodos. São Paulo: Oficina de Textos, 2008. 495 p.

SEBUSIANI, H. R. V.; BETTINE, S. D. C. Metodologia de análise do uso e ocupação do solo em micro bacia urbana. Revista Brasileira de Gestão e Desenvolvimento Regional, v. 7, n. 1, 2011. ISSN 1809-239X. Disponível em: < https://www.puccampinas.edu.br/websist/portal/ceatec/hidro/subprojetos/arquivos/Artigo Revista He lena.pdf $>$

SEPLAN. SECRETÁRIA DO PLANEJAMENTO E MEIO AMBIENTE. Perfil Socioeconômico dos Municípios do Tocantins, 2013. Disponível em: < http://www.seplan.to.gov.br > Acesso em 03 de Agosto de 2015

SILVA-NETO, C. D. M. E. S.; OKANO, S. F.; CARNEIRO, V. A.; GONÇALVES, B. B. Ocupação de Áreas de Preservação Permanentes dos Canais Fluviais em Ambiente Urbano do Município de Jataí-GO. Revista Percurso, v. 5, n. 2, p. 73-89, 2013. Disponível em: < http://dx.doi.org/10.4025/revpercurso.v5i2.21381 > doi: 10.4025/revpercurso.v5i2.21381

TRABAQUINI, K.; TAKEDA, M. M. G.; ROMAGNOLLI, R.; BARROS, M. V. F. Uso e ocupação das APPs em áreas de fundo de vale no perímetro urbano de LondrinaPR, utilizando imagem de alta resolução. RA'EGA - O Espaço Geográfico em Análise, v. 18, n. 2, p. 41-49, 2009. Disponível em: < http://dx.doi.org/10.5380/raega.v18i0.13996 > doi: 10.5380/raega.v18i0.13996

TSUJII, P. K.; RIBEIRO, A. C. C.; CARNEIRO, V. A.; NETO, C. D. M. E. S.; GONÇALVES, B. B. Uso e ocupação das Áreas de Preservação Permanentes no Sudoeste Goiano. Revistade Geografia (UFPE) v. 31, n. 3, p. 43-60, 2014. Disponível em: < http://www.revista.ufpe.br/revistageografia/index.php/revista/article/view/776/576 >

ZANZARINI, R. M.; ROSOLEN, V. Mata ciliar e nascente no Cerrado brasileiro: análise e recuperação ambiental. Geografia: Ensino \& Pesquisa, v. 12, p. 701-712, $2008 . \quad$ Disponível em: < http://www.observatoriogeograficoamericalatina.org.mx/egal12/Procesosambientales Impactoambiental/72.pdf > 